\title{
Microanalysis of Islamic Enameled Glass
}

\author{
M.T. Wypyski*
}

* Department of Scientific Research, The Metropolitan Museum of Art, 1000 Fifth Avenue, New York, NY 10028

The development of gilded and enameled glass in the Islamic world has been described as, "one of the most significant contributions to the history of glassmaking worldwide." Beginning in Syria and Egypt during the late Ayyūbid period (ca. 1169-1260) and continuing under the Mamluk sultans (1250-1517) in Syria and Egypt, for about two centuries glass artists created many different kinds of enameled objects, including bottles, beakers, basins, and lamps, many with calligraphic inscriptions in addition to abstract and figural decoration [FIG. 1]. In order to better understand their manufacture and characterize the materials used, quantitative chemical analyses were performed on a group of enameled vessels dated to the thirteenth to fourteenth centuries from the collection of The Metropolitan Museum of Art [1]. Micro-samples of the glass substrates and enamels were analyzed using energy dispersive and wavelength dispersive X-ray spectrometers in the scanning electron microscope (SEM-EDS/WDS). EDS was used to measure major and minor components present, while small amounts below 1 percent by weight were determined using WDS.

The colorless vessel glasses were found to have soda-lime-silica compositions, with soda averaging about 13 percent by weight, and lime slightly over 8 percent. All of the glasses contain relatively high levels of magnesia and potash as well, ranging from about 2 to 4 percent, with an average ratio of about 4 to 3 . Relatively small amounts of alumina, averaging about 1.2 percent, were also found in the glasses, as well as small amounts or traces of phosphorus, sulfur, chlorine, titanium, iron, strontium and barium. Manganese oxide, used to decolorize the glass, is also present, generally in about a 2 to 1 ratio with iron oxide.

Blue enamels have a similar overall composition to the vessel glass, although most contain much more aluminum and sulfur. Light microscope examination of the enamel samples revealed that they consist of a mixture of blue and colorless particles. Analysis of individual particles within the enamel show that colorless particles are essentially the same as the vessel glass, while the blue particles consist mainly of sodium, aluminum, silicon and sulfur, and appear to be the semi-precious stone lapis lazuli [FIG. 2]. One example of blue enamel was found which was colored solely with cobalt oxide, and does not contain any lapis particles. Red enamel also consists mainly of colorless soda-glass particles, but is mixed with fine particles of red iron oxide, presumably hematite [FIG. 3]. White enamels contain either crystalline tin oxide in a leaded-glass matrix, or are opacified with calcium phosphate particles, probably in the form of ground up bone. Several examples were also found which contain a mixture of both opacifiers [FIG. 4]. Yellow and green enamels differ from the other colors having lead-silicate compositions, containing about 50 to 70 percent lead oxide. These enamels are opacified with abundant yellow lead-tin crystals, with the green enamels also containing copper oxide. Three examples of relatively uncommon black enamel were also analyzed, and found to contain particles of the brown-black mineral chromite.

References

[1] M.T. Wypyski, Metropolitan Museum Studies in Art, Science and Technology. 1 (2010) 109. 
FIG. 1. Mosque lamp. Egypt or Syria, Mamluk, ca. 1325. Glass, enamels, gilding. Height $26.7 \mathrm{~cm}$, Diameter $20.8 \mathrm{~cm}$. The Metropolitan Museum of Art, Edward C. Moore Collection, Bequest of Edward C. Moore, 1891 (91.1.1534).
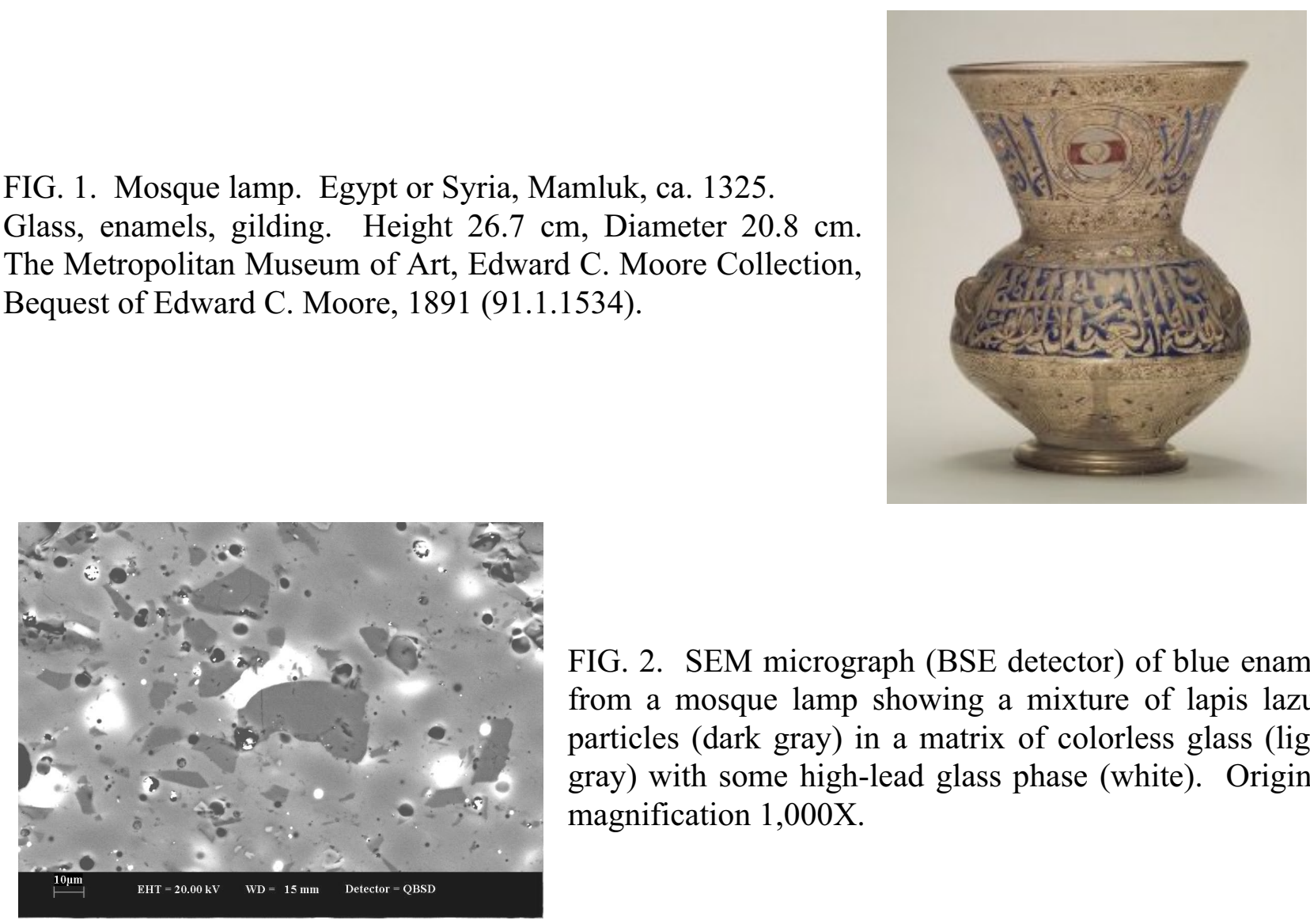

FIG. 2. SEM micrograph (BSE detector) of blue enamel from a mosque lamp showing a mixture of lapis lazuli particles (dark gray) in a matrix of colorless glass (light gray) with some high-lead glass phase (white). Original magnification $1,000 \mathrm{X}$.

FIG. 3. SEM micrograph (BSE detector) of red enamel showing colorless glass particles (gray) surrounded by red hematite particles (white). Original magnification $1,000 \mathrm{X}$.
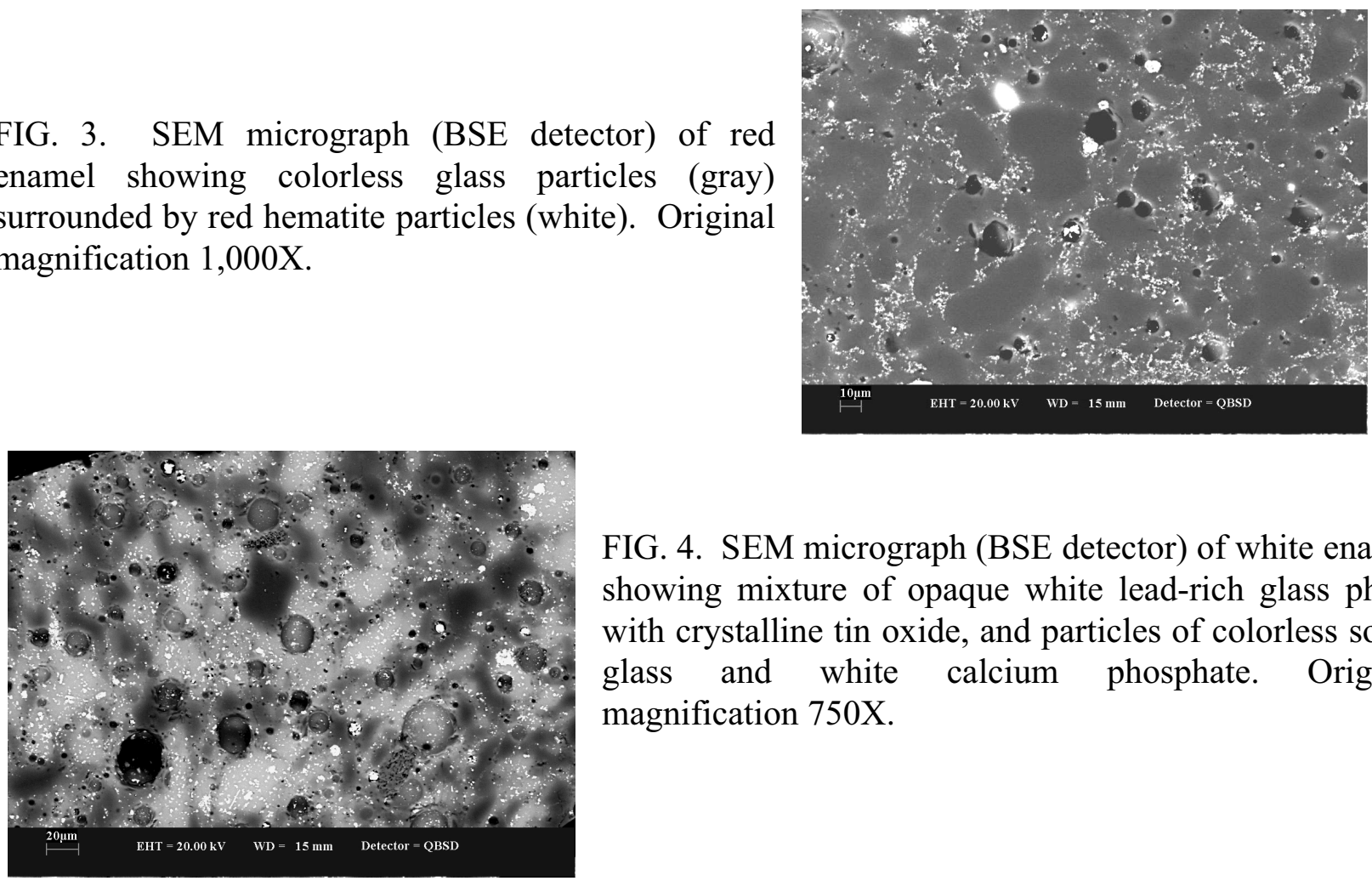

FIG. 4. SEM micrograph (BSE detector) of white enamel showing mixture of opaque white lead-rich glass phase with crystalline tin oxide, and particles of colorless sodaglass and white calcium phosphate. Original magnification $750 \mathrm{X}$. 